\title{
Realised response to short-term selection of the common pheasant (Phasianus colchicus) selected for seven-week body weight
}

\author{
David Zapletal', Eva Straková ${ }^{\text {and Pavel Suchý }}$ \\ 'Department of Animal Husbandry and Animal Hygiene, ${ }^{2}$ Department of Animal Nutrition, Faculty of Veterinary \\ Hygiene and Ecology, University of Veterinary and Pharmaceutical Sciences Brno, Czech Republic
}

\begin{abstract}
The aim of this study was to evaluate the effect of the directed positive selection of the common pheasant for a higher seven-week body weight (BW) relative to their gender on the realised response to the selection and adult (40-week) BW after four generations of selection. The founder population was not selected before for any traits. For the selection in generation one of the experiment, a total of 2080 pheasant chicks were used to establish a selection line (SL). In the same year, a total of 400 pheasant chicks were randomly selected as a control line (CL). Within the $\mathrm{SL}$, chicks from individual hatches were selected by sex, always based on live BW at the age of 49 days. The targeted selection was carried out for four generations. In all generations it was found a higher seven-week BW in males compared to females $(P<0.01)$. In generations two, three and four, the BW of the $S L$ in both sexes was always higher in comparison with the $\mathrm{CL}(P<0.01)$. The genetic improvement of the seven-week BW was $15.0,6.4$ and $10.1 \mathrm{~g}$ in generation two, three and four, respectively. In the last generation, the increase in the seven-week BW of the SL compared to the $\mathrm{CL}$ was higher in females than in males ( 8.00 and $6.66 \%$, respectively). The realised heritability for the seven-week BW was 0.19. The selection at the age of seven weeks also caused an absolute increase in BW of adult pheasants at the age of 40 -weeks.
\end{abstract}

Keywords: pheasant, captive breeding, gender, genetic improvement, heritability

Abbreviations: $B W$ : body weight, $\mathrm{CL}$ : control line, $\mathrm{CP}$ : crude protein, $\mathrm{SL}$ : selection line

Archiv Tierzucht 56 (2013) 67, 675-683

doi: $10.7482 / 0003-9438-56-067$

Corresponding author:

David Zapletal; email: zapletald@vfu.cz

Department of Animal Husbandry and Animal Hygiene, Faculty of Veterinary Hygiene and Ecology, University of Veterinary and Pharmaceutical Sciences Brno, Palackého tř. 1/3, 61242 Brno, Czech Republic

() 2013 by the authors; licensee Leibniz Institute for Farm Animal Biology (FBN), Dummerstorf, Germany. This is an Open Access article distributed under the terms and conditions of the Creative Commons Attribution 3.0 License (http://creativecommons.org/licenses/by/3.0/).
Received: 28 January 2013

Accepted: 19 March 2013 Online: 24 May 2013 


\section{Introduction}

In general, pheasant meat has a high nutritional value, as it contains high-quality protein and little fat and so there is a strong market demand for it, especially considering the increasing consumer interest in safe food products (Straková et al. 2006, Kuźniacka \& Adamski 2010, Straková et al. 2011).

The success of poultry production has been strongly related to improvements in growth and carcass yield (Le Bihan-Duval et al. 2001). As the heritability of BW is moderate to high, the selection has largely contributed to this trait (Le Bihan-Duval et al. 2001, Larivière et al. 2009). Rémignon (2004) states that in Europe, more than $95 \%$ of pheasants are reared for hunting and the selection depends more on their ability to fly and capacity for survival in the wild than their productivity or growth performance. We have recently seen their goaldirected fattening for the purposes of meat production as part of the captive breeding of pheasants in some European countries (Mašek et al. 2007, Kokoszynski et al. 2011, Straková et al. 2011), similar to the now relatively common practice in North America where even a white pheasant has been developed that is reared artificially and marketed as traditional poultry (Rémignon 2004). According to Roberson (2004) the white pheasant is a meatier type of pheasant that has been developed through crossbreeding to provide a larger bird with a higher breast yield than the ring-necked pheasant. Nevertheless in Europe, mentions of the directed selection or hybridisation of meat-type pheasants are currently more likely to be sporadic (Zapletal et al. 2011, Kokoszynski et al. 2012).

The aim of this study was to evaluate the effect of the directed positive selection of the common pheasant (Phasianus colchicus) for a higher seven-week body weight (BW) relative to their gender on the realised response to the selection and adult (40-week) BW after four generations of selection.

\section{Material and methods}

\section{Birds}

The experiment was performed in the pheasantry of the University of Veterinary and Pharmaceutical Sciences Brno (305 m above sea level; GPS: 49¹5'44.383" N, 16³2'1.300" E), Czech Republic. The experimental birds were common pheasants (Phasianus colchicus) while the used founder population ( 75 males and 375 females, generation 0 ) was not selected before for any trait. For the selection in the second year of the experiment, a total of 2080 pheasant chicks (1 041 males and 1039 females) were used to establish a selection line (SL). In the same year, a total of 400 pheasant chicks were randomly selected as a control line (CL). Within the $\mathrm{SL}$, chicks from individual hatches were selected by sex, always based on live weight at the age of 49 days and correct physical development. Positively selected chicks were marked with a leg ring and used in the next year as a parental flock (generation one). In each year of the experiment, the randomly selected birds within the $\mathrm{CL}$ were weighed at the age of 49 days. Individuals from this group were then randomly selected to form a parental flock of the $\mathrm{CL}$ in the following year. This work evaluates the targeted selection of pheasants for a higher body weight at the age of seven weeks over four generations. The number of used parents and evaluated progeny is stated in Table 1 by line, sex and generation. Table 2 shows the selection 
intensity expressed in \% which represents the proportion of birds positively selected from the overall group assessed, within sex and specific hatching in individual generations.

Table 1

Number of parents and progeny in each line by sex and generation

\begin{tabular}{|c|c|c|c|c|c|c|c|c|c|c|c|c|c|c|}
\hline \multirow{3}{*}{$\begin{array}{l}\text { Genera- } \\
\text { tion }\end{array}$} & \multicolumn{10}{|c|}{ Selected line } & \multicolumn{4}{|c|}{ Control line } \\
\hline & \multicolumn{2}{|c|}{ Parents } & \multicolumn{2}{|c|}{ Hatch 1} & \multicolumn{2}{|c|}{ Hatch 2} & \multicolumn{2}{|c|}{ Hatch 3} & \multicolumn{2}{|c|}{ Hatch 4} & \multicolumn{2}{|c|}{ Parents } & \multicolumn{2}{|c|}{ Progeny } \\
\hline & Sire & Dam & Male & Female & Male & Female & Male & Female & Male & Female & Sire & Dam & Male & Female \\
\hline 0 & 50 & 250 & - & - & - & - & - & - & - & - & 25 & 125 & - & - \\
\hline 1 & 50 & 250 & 237 & 222 & 298 & 307 & 292 & 271 & 214 & 239 & 29 & 176 & 200 & 200 \\
\hline 2 & 49 & 245 & 111 & 102 & 304 & 317 & 215 & 213 & - & - & 15 & 75 & 150 & 150 \\
\hline 3 & 42 & 252 & 191 & 175 & 236 & 234 & 207 & 214 & - & - & 20 & 120 & 150 & 150 \\
\hline 4 & 38 & 190 & 199 & 196 & 232 & 249 & 115 & 112 & - & - & 30 & 150 & 150 & 150 \\
\hline
\end{tabular}

Table 2

Intensity of selection (\%) by hatch and generation in selection line

\begin{tabular}{lcccccccccc}
\hline & \multicolumn{2}{c}{ Hatch 1 } & \multicolumn{2}{c}{ Hatch 2 } & \multicolumn{2}{c}{ Hatch 3 } & \multicolumn{2}{c}{ Hatch 4 } & \multicolumn{2}{c}{ Mean } \\
Generation & Male & Female & Male & Female & Male & Female & Male & Female & Male & Female \\
\hline 1 & 5.49 & 24.32 & 6.04 & 27.69 & 4.80 & 27.68 & 4.67 & 25.94 & 5.28 & 26.56 \\
2 & 8.11 & 43.14 & 8.88 & 42.27 & 7.91 & 42.72 & - & - & 8.41 & 42.56 \\
3 & 7.33 & 43.43 & 7.20 & 43.16 & 7.25 & 45.79 & - & - & 7.26 & 44.14 \\
4 & 11.60 & 47.45 & 9.05 & 46.19 & 10.44 & 41.07 & - & - & 10.07 & 45.60 \\
\hline
\end{tabular}

After hatching and within each hatch of the $S \mathrm{~L}$ and $\mathrm{CL}$, the chicks were placed in separate aviaries in the indoor housing with the same environmental conditions. After weighing at the age of seven weeks, the groups of positively selected chicks from individual hatches as well as the control group were placed in separate outdoor aviaries enabling access to the indoor housing. Pheasants were housed in this manner until the age of 40 weeks when they were weighed again. After the second weighing and within the particular line, the adult pheasants were housed together in one large outdoor aviary. Formation of specific breeding groups (1 male : 5-6 females) within the lines was random, in the period between the 20th and 31st of March. Breeding groups created in this way were housed in cages under an outdoor shelter throughout the breeding period. Egg collection for the experimental purposes started on the 20th of April. Eggs were collected twice a day and stored up to 14 days at a temperature of $14^{\circ} \mathrm{C}$ and humidity of $70 \%$ separately according to the line. Eggs of each line were incubated in separated trays. Within the $\mathrm{SL}$, four and three hatches in generation one and generations two, three and four were performed, respectively.

In the course of rearing, the pheasant chicks were nourished by commercially manufactured complete feed mixtures - starter for turkeys ( $28 \%$ crude protein (CP) and $11.6 \mathrm{MJ}$ of ME/kg) until the age of five days, feed mixture BŽ 1 (26\% CP and $11.7 \mathrm{MJ}$ of ME/ $\mathrm{kg}$ ) from 6 to 14 days, feed mixture $B Z ̌ Z 2$ ( $24 \% \mathrm{CP}$ and $12.0 \mathrm{MJ}$ of ME $/ \mathrm{kg}$ ) from 15 to 28 days, and feed mixture $B \check{Z} 3(13 \% \mathrm{CP}$ and $12.3 \mathrm{MJ}$ of ME/kg) from 29 to 70 days. From the $71 \mathrm{st}$ day of age, the feeding ration for pheasants was gradually converted into whole wheat grains; 
pheasants were fed in that manner until mid-February of the following year. Feed mixture BŽN ( $20 \%$ CP and $11.5 \mathrm{MJ}$ of ME/kg) was used to feed the breeding flock in the period from the end of February to the end of July. All used feeds in the experiment were made by ADW Agro, a.s. (Krahulov, Czech Republic). Food and water were available ad libitum throughout the experiment.

\section{Traits}

The most important selection criterion for the pheasant chicks was the BW with respect to sex in 49 days of age. This age was determined on the basis of previous work finding that the pheasant chicks reached the highest intensity of growth rate during the period between days 41 and 70 (Straková et al. 2005). Based on morphological traits, it was possible to distinguish the sex of pheasant chicks at the age of 49 days. When selecting the chicks, we also consider their correct physical development; particularly, birds with deformities of breastbone, legs, toes and beak were rejected.

Subsequently, the positively selected birds in the SL and selected breeding birds in the $\mathrm{CL}$ were weighed at the age of 40 weeks, i. e. before the beginning of their breeding period in the following year.

\section{Statistical analysis}

Statistical analyses were performed using STATISTICA CZ v. 9 (StatSoft, Inc. Tulsa, OK, USA). Comparison of the means of BWs in pheasant chicks at the age of seven weeks was done using the following generalised linear model:

$$
Y_{i j k l}=\mu+L_{i}+S_{j}+G_{k}+L_{i} \times S_{j}+e_{i j k l^{\prime}}
$$

where $Y_{i j k l}$ was an individual observation for the trait $Y, \mu$ was the overall mean, $L_{i}$ was the fixed effect of the $i$ th line $(i=S, C), S_{j}$ was the fixed effect of the $j$ th sex, $G_{k}$ was the fixed effect of the $k$ th generation $(k=1,2,3,4), L_{i} \times S_{j}$ was the fixed interaction of $L_{i}$ and $S_{j}$, and $e_{i j k l}$ was a residual random effect (Table 3 ). A comparison of the means of BWs in adult pheasants at the age of 40 weeks was done by multi-factorial ANOVA (Table 5). The Kolmogorov-Smirnov test was used to test the normality of the distribution in particular groups.

The realised heritability for the seven-week BW was calculated as the ratio of the cumulative selection response to the cumulative selection differential (Falconer \& Mackay 1996, Khaldari et al. 2010).

\section{Results}

During the entire assessment period of the seven-week BW (generations one to four), a higher BW of pheasants was found in chicks of the SL $(433.6 \pm 1.05 \mathrm{~g})$ compared to the $\mathrm{CL}$ $(402.4 \pm 1.69 \mathrm{~g})$. Moreover, the coefficient of variation was slightly smaller in the SL (17.1) compared to the $\mathrm{CL}$ (17.7).

The seven-week BW of pheasant chicks by sex, line and generation is presented in Table 3. In generation one and within both sexes, we found no statistical difference between the SL and $C L$ with regard to the average BW. In this generation, a lower BW was observed only in females $(P<0.01)$ compared to males (not shown in table). In the following generations, the BW 
of the $S L$ in both sexes was always higher in comparison with the $C L(P<0.01)$. In generations two, three and four, a higher BW in males $(P<0.01)$ than in females was confirmed (not shown in table). In males of the $\mathrm{SL}$, the highest BW was found in the last generation; regarding generation three, the BW was reduced in comparison with the previous generation two $(P<0.01)$. Similarly, the females of the SL reached the highest BW also in generation four while the lowest BW was found in generation three; this BW was lower compared to generation two as well as to generation one $(P<0.01)$. In the $C L$ and within both sexes, we also confirmed a different BW between particular generations. The body weight in males of generation two and four was higher compared to generations one and three whereas the lowest BW was found in generation three $(P<0.01)$, much like in males in the SL. In females, the highest BW appertained to generation four while the lowest BW was observed in generation three $(P<0.01)$ which indicated a similar trend as in females of the $S L$.

Table 3

Seven-week BW of pheasants by sex, line, and generation (LSM \pm SE)

\begin{tabular}{lcccccc}
\hline & \multicolumn{2}{c}{ Male } & \multicolumn{2}{c}{ Female } & \multicolumn{2}{c}{$P$} \\
Generation & $\mathrm{SL}, \mathrm{g}$ & $\mathrm{CL}, \mathrm{g}$ & $\mathrm{SL}, \mathrm{g}$ & $\mathrm{CL}, \mathrm{g}$ & $0^{\mathrm{A}}$ & \% \\
\hline 1 & $453.2 \pm 1.86^{\mathrm{A}}$ & $456.1 \pm 3.69^{\mathrm{B}}$ & $374.2 \pm 2.42^{\mathrm{B}}$ & $370.9 \pm 3.74^{\mathrm{B}}$ & $\mathrm{ns}$ & $\mathrm{ns}$ \\
2 & $497.8 \pm 1.94^{\mathrm{B}}$ & $484.3 \pm 3.97^{\mathrm{C}}$ & $379.9 \pm 2.51^{\mathrm{B}}$ & $363.4 \pm 3.40^{\mathrm{B}}$ & $* *$ & $* *$ \\
3 & $456.0 \pm 1.90^{\mathrm{A}}$ & $437.5 \pm 3.43^{\mathrm{A}}$ & $363.6 \pm 2.15^{\mathrm{A}}$ & $339.1 \pm 3.25^{\mathrm{A}}$ & $* *$ & $* *$ \\
4 & $515.7 \pm 2.84^{\mathrm{C}}$ & $483.5 \pm 4.07^{\mathrm{C}}$ & $417.0 \pm 2.63^{\mathrm{C}}$ & $386.1 \pm 4.89^{\mathrm{C}}$ & $* *$ & $* *$ \\
\hline
\end{tabular}

LSM: least square mean, SE: standard error of the mean, ns: not significant, ${ }^{A B C}$ Within a column, values with different superscripts are significantly different at $P<0.01,{ }^{* *}$ Within a row and a sex, values are significantly different at $P<0.01$

The selection response for the seven-week BW is shown in Table 4. Genetic improvement was $15.0,6.4$ and $10.1 \mathrm{~g}$ for generation two, three and four, respectively. For the entire evaluated period of targeted selection, this represented a genetic improvement of $31.5 \mathrm{~g}$. Concretely in males, the BW increase in generation four within the $\mathrm{SL}$ reached $32.2 \mathrm{~g}$ compared to the $\mathrm{CL}$ which represents an increase of $6.66 \%$. In females, the BW increase in generation four within the $\mathrm{SL}$ was $30.9 \mathrm{~g}$ compared to the $\mathrm{CL}$ which represents an increase of $8.00 \%$. Discovered realised heritability for the seven-week BW of pheasants was 0.19 .

Table 4

Selection response for 7 -week $B W$ and selection differential ${ }^{1}$

\begin{tabular}{lccccccccc}
\hline \multirow{2}{*}{$\begin{array}{l}\text { Gener- } \\
\text { ation }\end{array}$} & \multicolumn{2}{c}{ Population mean } & \multicolumn{2}{c}{ Selected Selection } & \multicolumn{2}{c}{ Response } & \multicolumn{2}{c}{ Corrected response } & \multicolumn{2}{c}{ Selection differential } \\
SL & CL & mean & differential & SL & CL & SL & Male & Female \\
\hline 0 & 411.8 & 413.1 & - & - & - & - & - & - & - \\
1 & 413.6 & 413.5 & 458.6 & 45.0 & - & - & - & 59.1 & 30.6 \\
2 & 438.9 & 423.8 & 506.5 & 67.6 & 25.3 & 10.3 & 15.0 & 78.5 & 56.7 \\
3 & 409.8 & 388.3 & 465.6 & 55.8 & -29.1 & -35.5 & 6.4 & 67.9 & 43.6 \\
4 & 466.4 & 434.8 & - & - & 56.6 & 46.5 & 10.1 & - & - \\
Sum & & & & 168.4 & & & 31.5 & & \\
\hline
\end{tabular}

${ }^{1}$ Realized heritability $=31.5 / 168.4=0.19$. 
The forty-week BW of breeding pheasants within sex, line and generation is stated in Table 5 . Within both sexes in particular generations, the positively selected parents of the SL always reached a higher 40-week BW $(P<0.01)$ than parents from the $C L$ (not shown in the table). In sires of the $S L$, the highest BW was conclusively found in the last generation, the lowest BW in generation two was lower than in generation one $(P<0.01)$. Over four generations of targeted selection, the 40 -week BW in positively selected sires of the SL increased by $10.35 \%$. Regarding the sires of the $\mathrm{CL}$ and generation four, a higher BW was found only compared to generation one $(P<0.01)$. Due to the selection, the differences between the $\mathrm{SL}$ and $\mathrm{CL}$ regarding the BWs of sires increased by $8.17 \%$ - from generation one $(+17.94 \%$ for the $S L)$ to generation four ( $+26.11 \%$ for the $\mathrm{SL}$ ). In positively selected dams of the SL, the highest BW was observed in the last generation four $(P<0.01)$, besides dams of generation two displayed higher BWs than dams of generation one $(P<0.05)$. Over four generations of the targeted selection, the 40 -week BW in dams of the $S L$ increased by $9.11 \%$. Concerning dams of the $C L$, we also detected a different BW in particular generations $(P<0.01)$; the BW in generation three and four was higher than in generations one and two. However, a comparison of differences in the BW between dams of the $S L$ and $C L$ indicates that the overall decrease makes $4.48 \%$ from generation one $(+15.56 \%$ for the $\mathrm{SL})$ to generation four $(+11.08 \%$ for the $\mathrm{SL})$.

Table 5

Forty-week BW of adult breeding pheasants by sex, line, and generation ( $x \pm S E)$

\begin{tabular}{lcccccc}
\hline \multirow{2}{*}{ Generation } & \multicolumn{2}{c}{ Sire } & \multicolumn{2}{c}{ Dam } & \multicolumn{2}{c}{$P$} \\
\hline 1 & $1624 \pm 13.3^{\mathrm{B}}$ & $1377 \pm 18.2^{\mathrm{A}}$ & $1307 \pm 5.9^{\mathrm{A}, \mathrm{a}}$ & $1131 \pm 6.8^{\mathrm{A}}$ & $* *$ & $* *$ \\
2 & $1528 \pm 16.7^{\mathrm{A}}$ & $1384 \pm 22.2^{\mathrm{A}, \mathrm{B}}$ & $1334 \pm 7.7^{\mathrm{A}, \mathrm{b}}$ & $1186 \pm 14.1^{\mathrm{B}}$ & $* *$ & $* *$ \\
3 & $1578 \pm 17.2^{\mathrm{A}, \mathrm{B}}$ & $1381 \pm 15.2^{\mathrm{A}, \mathrm{B}}$ & $1325 \pm 6.8^{\mathrm{A}, \mathrm{a}, \mathrm{b}}$ & $1254 \pm 13.8^{\mathrm{C}}$ & $* *$ & $* *$ \\
4 & $1792 \pm 31.0^{\mathrm{C}}$ & $1421 \pm 17.6^{\mathrm{B}}$ & $1426 \pm 7.9^{\mathrm{B}}$ & $1268 \pm 12.4^{\mathrm{C}}$ & $* *$ & $* *$ \\
\hline
\end{tabular}

$\mathrm{x}$ : mean, SE: standard error of the mean, ${ }^{\mathrm{ABC}}$ Means within a column are significantly different at $P<0.01$, ${ }^{\text {ab }}$ Means within a column are significantly different at $P<0.05,{ }^{*}$ Within a row and a sex, values are significantly different at $P<0.01$

\section{Discussion}

\section{Genetic improvement}

The mean seven-week BW of the SL and CL in the last evaluated generation was 466.4 and $434.8 \mathrm{~g}$, respectively, which resulted in a $7.3 \%$ cumulative genetic improvement or $2.4 \%$ improvement per generation. In a similarly organised experiment with a selection of Japanese quails for a higher BW, Khaldari et al. (2010) reached a 5.8\% genetic improvement per generation which is a considerably higher level than in our selection of pheasants. Arthur \& Albers (2003) report that the selection of broiler chickens for a higher growth intensity in the period of 1960 to 2000 increased by an average daily gain of $3.2 \%$ per year. Havenstein et al. (1994) note that the progress in growth rate in broiler chickens at this time can be attributed to genetic improvement for $80 \%$ which represents about $2.6 \%$ per year. This level of genetic improvement in broiler chickens would be consistent with the results observed 
in our evaluation of the seven-week BW in pheasants. An actual result of the selection for increased growth is generally affected by the selection intensity, timing, selection method and genetic variance in population (Emmerson 2003, Khaldari et al. 2010). Although a significantly higher intensity of selection was chosen in males (5.3 to 10.1\%) compared to females (26.6 to $45.6 \%$ ), the BW then increased similarly in both sexes. Specifically, the seven-week BW in the SL generation four was higher by $6.7 \%$ in males and $8.0 \%$ in females compared to the CL. In meat-type chickens selected for a higher eight-week BW, MignonGrasteau et al. (1999) found that the difference between the $S L$ and $C L$ was higher in males than in females; nevertheless, their evaluation monitored a total of 10 generations. In the last generation four of our experiment, the seven-week BW of males in the SL was higher by $23.7 \%$ compared to females; regarding the $\mathrm{CL}$, the males outweighed females by $25.2 \%$. By contrast, Mignon-Grasteau et al. (1999) report that the difference in the eight-week BW between males and females tended to be higher in lines selected for a high eight-week BW compared to the non-selected line.

In the experimental evaluation focused on fattening of pheasant chicks, Straková et al. (2005) found that the highest growth intensity was reached between days 41 and 70 . Based on this previous work, we determined the age for selection to seven weeks. At this age, we were already able to distinguish sexes and there was an assumption that a targeted selection around the inflection point can improve their growth efficiency (Hyánková et al. 2001, Nahashon et al. 2006). The targeted selection of pheasant chicks for a high seven-week BW in our experiment also led to an absolute increase in BW of adult pheasants in the SL compared to the $\mathrm{CL}$, in all years of selection and within both sexes $(P<0.01)$. In general, selection at an early age appears to change the shape of the growth curve resulting in an earlier point of inflection and a greater slope at the point of inflection. In contrast, selection at a later age increases the magnitude of growth without significantly changing the form of growth (Emmerson 2003). In our case, due to the selection in the vicinity of the point of inflection, we observed not only an increase in the growth intensity until the age of seven weeks but also an absolute increase in BW of adult pheasants. When comparing BW differences between generations one and four of the 40-week parents in the $\mathrm{SL}$, it is clear that sires achieved a higher increase in BW than dams $(10.35 \%$ vs. $9.11 \%$, respectively). Analogously, also Supriyantono (2009) discovered a higher increase in BW for males than for females in broiler chickens. Nevertheless, as the pheasants were housed in outdoor aviaries from the age of seven weeks, their own 40 -week BW might be also influenced by specific climatic conditions of the winter season in particular years.

\section{Realised heritability}

In an unselected population of common pheasants, Rizzi et al. (1994) identified $\mathrm{h}^{2}$ estimates (sire component) 0.27 and 0.30 for BW at 28 and 120 days, respectively, and note that the magnitude of heritability indicates that selection for the BW in pheasants is possible - which is also confirmed by the results of our experiment. In our case, the realised $\mathrm{h}^{2}$ of the sevenweek BW after selection was 0.19 . The estimated $\mathrm{h}^{2}$ for BW in chickens is reported in the range of 0.19 to 0.42 (Gaya et al. 2006, Larivière et al. 2009, Supriyantono 2009). In Japanese quail, Khaldari et al. (2010) found $\mathrm{h}^{2}$ estimate for the four-week BW, after the same length of 
selection like in our experiment, at the level of 0.26 . Concerning the realized $h^{2}$ of the BW in poultry, Liu et al. (1994) revealed in broiler chickens that $h^{2}$ of the eight-week BW ranged from 0.22 to 0.28 for high BW lines. Nestor et al. (2008) stated that $h^{2}$ of the 16 -week BW in turkeys were $0.31,0.27,0.24$ and 0.17 after selection in generations 1 to 10,11 to 20,21 to 30 and 31 to 40, respectively. Moreover, Supriyantono (2009) found a discrepancy in estimated and realised heritability in broiler chickens selected for nine generations. In his study, realised $h^{2}$ of the six-week BW was significantly lower than the estimated $h^{2}(0.10$ vs. 0.42$)$. In contrast, Khaldari et al. (2010) found a higher value for realized $h^{2}$ than for estimated $h^{2}$ in Japanese quails. In our experiment, we also found lower levels of realised $h^{2}$ for males compared to females ( 0.17 vs. 0.21 , respectively). A different level of realised $h^{2}$ between sexes in turkey was also reported by Nestor et al. (2008); however, they found higher $\mathrm{h}^{2}$ in males than in females (0.20 vs. 0.13 , respectively). In general, Falconer (1960) stated that the heritability for a particular trait can take different values according to the population, environmental conditions and the calculation method.

In conclusion, our results show that the targeted selection of pheasants for a higher seven-week BW, performed separately by sexes for the period of three generations, led to a $2.4 \%$ genetic improvement per generation whereas the realised $\mathrm{h}^{2}$ for the seven-week BW was 0.19 . The seven-week BW in generation four within the SL was higher by $6.7 \%$ in males and by $8.0 \%$ in females compared to the CL. The selection at the age of seven weeks also caused an absolute increase in BW of adult pheasants at the age of 40 weeks in generation four, especially in males. The four-year directional positive selection of pheasants performed within this work was a successful tool to increase the BW for the purpose of pheasant meat production.

\section{Acknowledgements}

This study was funded from the Grant Project of the Ministry of Agriculture of the Czech Republic NAZV No. QH 91276.

\section{References}

Arthur JA, Albers GAA (2003) Industrial Perspective on Problems and Issues Associated with Poultry Breeding. In: Muir WM, Aggrey SE (eds.) Poultry Genetics, Breeding and Biotechnology. CABI Publishing, Wallingford, UK, 1-12

Emmerson D (2003) Breeding Objectives and Selection Strategies for Broiler Production. In: Muir WM, Aggrey SE (eds.) Poultry Genetics, Breeding and Biotechnology. CABI Publishing, Wallingford, UK, 113-126

Falconer DS (1960) Selection of mice for growth on high and low planes of nutrition. Genet Res 1, 91-113

Falconer DS, Mackay TFC (1996) Introduction to quantitative genetics. 4. ed., Longman, London, UK

Gaya LG, Ferraz JBS, Rezende FM, Mourao GB, Mattos EC, Eler JP, Michelan Filho T (2006) Heritability and genetic correlation estimates for performance and carcass and body composition traits in a male broiler line. Poult Sci 85, 837-843

Havenstein GB, Ferket PR, Scheideler SE, Larson BT (1994) Growth, Liveability, and Feed Conversion of 1957 vs 1991 Broilers When Fed »Typical« 1957 and 1991 Broiler Diets. Poult Sci 73, 1785-1794

Hyánková L, Knížetová H, Dědková L, Hort J (2001) Divergent selection for shape of growth curve in Japanese quail. 1. Responses in growth parameters and food conversion. Br Poult Sci 42, 583-589 
Khaldari M, Pakdel A, Mehrabani Yegane H, Nejati Javaremi A, Berg P (2010) Response to selection and genetic parameters of body and carcass weights in Japanese quail selected for 4-week body weight. Poult Sci 89, 1834-1841

Kokoszyński D, Bernacki Z, Cisowska A (2011) Growth and development of young game pheasants (Phasianus colchicus). Arch Tierz 54, 83-92

Kokoszyński D, Bernacki Z, Duszyński L (2012) Body conformation, carcass composition and physicochemical and sensory properties of meat from pheasants of different origin. Czech J Anim Sci 57, 115-124

Kuźniacka J, Adamski M (2010) Growth rate of body weight and measurements in pheasants reared up to the 24th week of life. Arch Tierz 53, 360-367

Larivière JM, Michaux C, Verleyen V, Leroy P (2009) Heritability estimate and response to selection for body weight in the Ardennaise chicken breed. Int J Poult Sci 8, 952-956

Le Bihan-Duval E, Berri C, Baeza E, Millet N, Beaumont C (2001) Estimation of the genetic parameters of meat characteristics and of their genetic correlations with growth and body composition in an experimental broiler line. Poult Sci 80, 839-843

Liu G, Dunnington EA, Siegel PB (1994) Response to Long-Term Divergent Selection for Eight-Week Body Weight in Chickens. Poult Sci 73, 1642-1650

Mašek T, Severin K, Horvatek D, Janicki Z, Konjevic D, Slavica A, Mikulec Ž (2007) Serum parameters of intensively reared common pheasant (Phasianus colchicus) during fattening. Arch Geflügelkd 71, 135-138

Mignon-Grasteau S, Beaumont C, Le Bihan-Duval E, Poivey JP, De Rochambeau H, Ricard FH (1999) Genetic parameters of growth curve parameters in male and female chickens. Br Poult Sci 40, 44-51

Nahashon SN, Aggrey SE, Adefope NA, Amenyenu A (2006) Modeling growth characteristics of meat-type guinea fowl. Poult Sci 85, 943-946

Nestor KE, Anderson JW, Patterson RA, Velleman SG (2008) Genetics of Growth and Reproduction in the Turkey. 17. Changes in Genetic Parameters Over Forty Generations of Selection for Increased Sixteen-Week Body Weight. Poult Sci 87, 1971-1979

Rémignon H (2004) Production of turkeys, geese, ducks and game birds. In: Mead GC (ed.) Poultry meat processing and quality. Woodhead Publishing, Cambridge, UK, 211-231

Rizzi R, Cerolini S, Mantovani C, Pagnacco G, Mangiagalli MG, Cavalchini LG (1994) Heritabilities and Genetic Correlations of Conformation and Plumage Characteristics in Pheasant (Phasianus colchicus). Poult Sci 73, 1204-1210

Roberson KD (2004) White Pheasant Production: Evaluation of Brooding Space, Phase Feeding Method and Carcass Composition. Department of Animal Science, Michigan State University, East Lansing, MI, USA http://www.mwpoultry.org/ProjectPDFs/04-15.pdf [last accessed 04.06.2013]

Straková E, Suchý P, Karásková K, Jámbor M, Navrátil P (2011) Comparison of nutritional values of pheasant and broiler chicken meats. Acta Vet Brno 80, 373-377

Straková E, Suchý P, Vitula F, Večerek V (2006) Differences in the amino acid composition of muscles from pheasant and broiler chickens. Arch Tierz 49, 508-514

Straková E, Vitula F, Suchý P, Večerek V (2005) Growth intensity and carcass characteristics of fattened pheasant poults. Krmiva $47,73-82$

Supriyantono A (2009) Selection for Growth and Feed Efficiency in Broiler: Realized Heritability and Responses of Selection. In: Proc 1st Int Sem Anim Ind, Bogor, Indonesia, 380-387

Zapletal D, Vitula F, Straková E, Suchý P, Kroupa L (2011) The effect of selection on the growth rate of pheasant chicks in the 1st generation of offspring. In: Proc 18th Int Conf Krmiva, Zagreb, Croatia, 134-135 